\title{
Substituição parcial do cimento CPV-ARI por lodo de estação de tratamento de água (ETA)
}

\author{
Partial replacement of CPV-ARI cement by \\ water treatment plant sludge (WTS)
}

Elisandro Alexandre ${ }^{1}$, Caroline Angulski da Luz ${ }^{2}$

\author{
${ }^{1}$ PPGTP/UTFPR, Pato Branco, PR, Brasil. \\ e-mail: eng.elisandroalexandre@gmail.com \\ ${ }^{2}$ Departamento de Engenharia Civil/UTFPR, Pato Branco, PR, Brasil. \\ e-mail: angulski@hotmail.com
}

\section{RESUMO}

O lodo gerado durante o processo de tratamento da água para abastecer a população é descartado na maioria das vezes, de forma inadequada, nos corpos hídricos, causando negativos impactos ambientais. Neste contexto, o presente estudo visou à valorização do lodo de estação de tratamento de água (ETA) através da sua incorporação em cimento Portland. A metodologia consistiu em produzir pastas de cimento Portland de alta resistência inicial (CP V-ARI) contendo lodo de ETA em teores de substituição de 0,10 e $20 \%$. A resistência mecânica e os compostos hidratados foram avaliados por meio de testes de DRX, TG/DTG e MEV, além de calorimetria por condução. A substituição do cimento CPV-ARI por lodo de ETA reduziu a resistência à compressão, principalmente aos 7 dias. Foi possível observar uma maior formação de etringita nas amostras contento lodo de ETA, o que provavelmente influenciou negativamente o comportamento mecânico. No entanto, a incorporação dos compostos presentes no lodo de ETA na matriz cimentícia foi observada, mostrando que o emprego do lodo de ETA no cimento Portland pode indicar uma alternativa segura para a sua destinação final.

Palavras Chaves: Cimento, Lodo de ETA, Resistência mecânica, etringita

\section{ABSTRACT}

The sludge generated during the water treatment process to supply the population is most often improperly disposed of in the water bodies, causing negative environmental impacts. In this context, the present study aimed at the valorization of the water treatment plant sludge (ETA) through its incorporation in Portland cement. The methodology consisted of producing of Portland cement pastes (CP V-ARI) containing ETA sludge in substitution contents of 0,10 and $20 \%$. Mechanical strength and hydrated compounds were evaluated by XRD, TG / DTG and SEM tests, as well as conduction calorimetry. Replacing CPV-ARI cement by ETA sludge reduced compressive strength, especially at 7 days. It was possible to observe a higher formation of ettringite in the samples containing ETA sludge, which probably negatively influenced the mechanical behavior. However, the incorporation of the compounds present in the ETA sludge in the cementitious matrix was observed, showing that the use of ETA sludge in Portland cement may indicate a safe alternative for its final destination.

Keywords: Cement, water sludge, compressive strength, ettingite

\section{INTRODUÇÃO}

O lodo gerado nas estações de tratamento de água (ETA) é um resíduo não biodegradável, rico em minerais de silicatos e matéria orgânica, incorporado pelos produtos resultantes das substâncias químicas adicionadas na água bruta durante o processo de tratamento [1].

Muitas das restrições do lançamento do lodo de ETA nos corpos hídricos está associada às transformações do coagulante utilizado e de como suas reações químicas subsequentes podem vir a influenciar a bio- 
ta aquática, onde se deve ter um controle quanto às alterações nos parâmetros de qualidade da água, tais como: turbidez, DQO, série de sólidos e metais [2].

A ABNT NBR 10.004 [3] classifica o lodo de ETA como resíduo sólido, sendo que o mesmo apresenta particularidades que inviabilizam o seu lançamento na rede pública de esgoto ou corpos de água, exigindo assim, tecnologias específicas para o seu tratamento.

O aproveitamento de resíduos tem sido visto como uma atividade tecnicamente promissora no emprego de novos materiais no setor da construção civil. A reciclagem na construção civil pode também resultar na oferta de produtos alternativos, além de apresentar soluções técnicas mais viáveis para situações pontuais com ganho de eficiência no processo, economia de recursos, transporte e disposição dos resíduos [4].

Como a composição mineralógica deste lodo se assemelha com a do cimento Portland, dando destaque a sílica, alumina e óxido de ferro, a sua incorporação ao cimento pode ser uma alternativa tecnicamente viável.

Diferentes estudos já foram desenvolvidos objetivando apresentar um destino ambientalmente correto para o lodo de ETA. Andrade et al. [5] utilizaram o lodo de ETA como agregado reciclado fino na produção de argamassas, avaliando o desempenho do produto obtido. Os autores observaram que a absorção de água pelas argamassas aumentou com a adição de lodo de ETA. Em relação à resistência mecânica, as amostras com o resíduo apresentaram valores inferiores às de referência.

Sales et al. [6] avaliaram as propriedades mecânicas do concreto produzido com um composto de lodo de tratamento de água e serragem, o qual apresentou resistência à compressão de $11 \mathrm{MPa}$, caracterizando-o como um concreto leve não estrutural.

Ramirez [7] avaliou o emprego do lodo de ETA no concreto. Foram produzidas amostras com lodo úmido (coletado na unidade de filtração do lodo) e com lodo calcinado à $900^{\circ} \mathrm{C}$. $\mathrm{O}$ autor observou que o lodo úmido possui influência negativa na resistência à compressão do concreto, sendo que quanto maior o teor de substituição menor o valor atingido. Já, nos concretos produzidos com lodo calcinado, o autor percebeu que até $20 \%$ houve um aumento nas propriedades mecânicas do concreto.

Num artigo recente, Godoy et al [9] investigaram o potencial do uso do lodo de ETA calcinado (de 600 a $800{ }^{\circ} \mathrm{C}$ ) como adição em cimento Portland. Eles observaram que a o aumento da temperatura potencializou a característica pozolânica do resíduo e que à $700{ }^{\circ} \mathrm{C}$ uma alta atividade foi observada. A atividade pozolânica do lodo de ETA também foi observada no trabalho recente de Ruviaro [10].

Diferente dos trabalhos supramencionados, o presente estudo objetivou a substituição parcial do cimento Portland por lodo de ETA, não calcinado, avaliando se a adição interfere na resistência mecânica e no processo de hidratação.

\section{MATERIAIS E MÉTODOS}

A figura 1 apresenta um fluxograma do preparo do lodo de ETA e as demais etapas desde a elaboração das pastas até a avaliação das microestruturas.

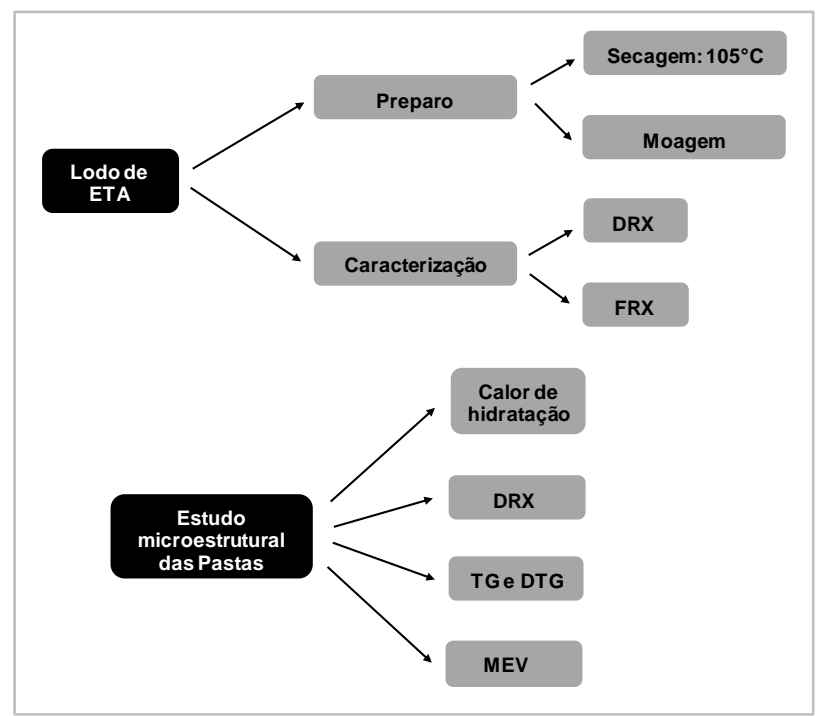

Figura 1: Fluxograma dos procedimentos realizados. 
O lodo de ETA passou pelo processo de secagem em estufa por 48 horas a uma temperatura controlada de $105^{\circ} \mathrm{C}$. Na sequência, utilizou-se o moinho de bolas por aproximadamente 12 horas e finalmente o almofariz e pistilo para finalizar a moagem do material. A Tabela 1 apresenta a composição química do lodo de ETA, obtida através da técnica de fluorescência de raios X (FRX), e do cimento Portland CPV-ARI, obtida junto ao fabricante Itambé (Tabela 1).

Tabela 1: Composição química e parâmetros físicos do lodo de ETA e do CPV-ARI.

\begin{tabular}{|c|c|c|c|c|c|c|c|c|c|c|c|c|}
\hline & $\begin{array}{c}\mathrm{Al}_{2} \mathrm{O}_{3} \\
(\%)\end{array}$ & $\begin{array}{c}\mathrm{SiO}_{2} \\
(\%)\end{array}$ & $\begin{array}{c}\mathrm{Fe}_{2} \mathrm{O}_{3} \\
(\%)\end{array}$ & $\begin{array}{l}\mathrm{TiO}_{2} \\
(\%)\end{array}$ & $\begin{array}{c}\mathrm{CaO} \\
(\%)\end{array}$ & $\begin{array}{c}\mathbf{P}_{2} \mathbf{O}_{5} \\
(\%)\end{array}$ & $\begin{array}{c}\text { MgO } \\
(\%)\end{array}$ & $\begin{array}{l}\mathrm{SO}_{3} \\
(\%)\end{array}$ & $\begin{array}{c}\mathrm{MnO} \\
(\%)\end{array}$ & $\begin{array}{l}\mathrm{K}_{2} \mathrm{O} \\
(\%)\end{array}$ & $\begin{array}{c}\text { Massa } \\
\text { específica } \\
\rho\left(\mathrm{g} / \mathrm{cm}^{3}\right)\end{array}$ & $\begin{array}{c}\text { Finura } \\
\text { (Blaine) } \\
\left(\mathrm{cm}^{2} / \mathrm{g}\right)\end{array}$ \\
\hline Lodo ETA & 25,8 & 24,2 & 19,3 & 2,9 & 0,6 & 0,4 & 0,4 & 0,3 & 0,3 & 0,2 & 2,1 & 12,820 \\
\hline CPV-ARI & 6,45 & 22,38 & 3,41 & - & 54,75 & - & 4,66 & 2,68 & - & - & 3,12 & 4,743 \\
\hline
\end{tabular}

Nota-se que os principais compostos químicos do cimento Portland também são encontrados no lodo de ETA. O teor de $\mathrm{SiO}_{2}$ é semelhante em ambos materiais, já o $\mathrm{Al}_{2} \mathrm{O}_{3}$ e o $\mathrm{Fe}_{2} \mathrm{O}_{3}$ aparecem em maior concentração no lodo. Por outro lado, o $\mathrm{CaO}$ é o composto químico de maior concentração no cimento, com mais de $50 \%$, enquanto no lodo o mesmo composto apresenta $0,60 \%$ da composição.

Através da técnica de difração de raios X (DRX), tem-se o difratograma exibido na Figura 2 do lodo de ETA. Observa-se que os picos característicos das fases cristalinas referem-se à caulinita $\left(\mathrm{Al}_{2} \mathrm{O}_{3} \cdot 2 \mathrm{SiO}_{2} \cdot 2 \mathrm{H}_{2} \mathrm{O}\right)$, quartzo $\left(\mathrm{SiO}_{2}\right)$ e gibsita $\left(\mathrm{Al}(\mathrm{OH})_{3}\right)$.

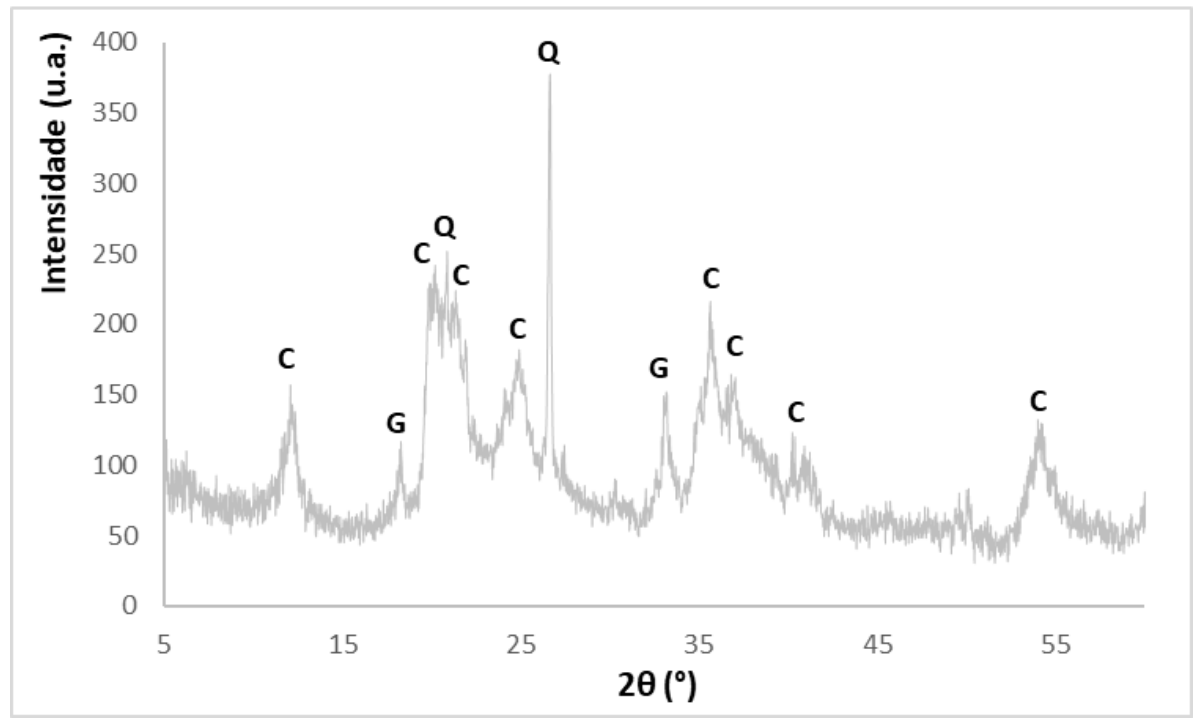

Figura 2: Difratograma do lodo de ETA, onde: Q - Quartzo, G - Gibsita e C - Caulinita.

O cimento Portland tipo CP V-ARI, foi substituído parcialmente por lodo de ETA nas proporções de 0,10 e $20 \%$. A presença de lodo da mistura alterou a consistência da mistura e, portanto, optou-se também por produzir pastas com aditivo superplastificante, de forma a manter a consistência e a relação água-cimento da referência (sem lodo de ETA), conforme Tabela 2. O uso de aditivo superplastificante foi baseado no trabalho de Alexandre et al. [8] onde foram observadas fissuras decorrentes da aglomeração do lodo na matriz cimentícia. Portanto. Portanto, o uso do aditivo também visou aumentar a fluidez da pasta para impedir a formação de novos aglomerados.

Tabela 2: Proporção dos materiais em massa utilizados em cada pasta (g).

\begin{tabular}{ccccc}
\hline Amostra & CPV & LETA & Aditivo & Água \\
\hline REF. & 100 & 0 & 0,0 & 40
\end{tabular}




\begin{tabular}{lllll}
$+10 \%$ LETA & 90 & 10 & 0,3 & 40 \\
$+10 \%$ LETA & 90 & 10 & 0,0 & 40 \\
$+20 \%$ LETA & 80 & 20 & 0,3 & 40 \\
$+20 \%$ LETA & 80 & 20 & 0,0 & 40 \\
\hline
\end{tabular}

A metodologia de preparo das pastas foi adaptada da ABNT NBR 7.215 [11]. Após o preparo, as amostras foram colocadas em câmara úmida $\left(23^{\circ} \mathrm{C}\right.$ e UR. $\left.95 \%\right)$, sendo desmoldadas após a idade de 24 horas. Em seguida, as amostras foram colocadas em recipientes mantidos em cura úmida até a idade de 28 dias.

As amostras foram submetidas ao teste de resistência à compressão nas idades de 7 e 28 dias.

As avaliações microestruturais das pastas foram obtidas por técnicas de difratometria de raios $\mathrm{X}$ (DRX), análise térmogravimétrica (TG/DTG) e microscopia eletrônica de varredura (MEV) para a idade de 28 dias. As condições para análise de TG/DTG foram: rampa de aquecimento de $10^{\circ} \mathrm{C} / \mathrm{min}$; faixa de $30^{\circ} \mathrm{C}$ a $1000^{\circ} \mathrm{C}$; atmosfera de gás inerte de $\mathrm{N}_{2}$ com vazão de $100 \mathrm{~mL} / \mathrm{min}$. Na análise de DRX os parâmetros foram: radiação $\mathrm{Cu} \mathrm{K \alpha} 1,54 \AA$; faixa de 5 a $60^{\circ}$; passo de $0,05^{\circ}$ s. As condições para o MEV foram: corrente de 15 $\mathrm{kV}$; amostras recobertas com ouro; com aumentos entre 50 a 2.000 vezes.

$\mathrm{O}$ calor de hidratação das pastas também foi medido num calorímetro isotérmico (Calmetrix) pelo período de 168 horas ( 7 dias) na temperatura de $23^{\circ} \mathrm{C}$.

\section{RESULTADOS E DISCUSSÃO}

\subsection{Calor de Hidratação}

As curvas da taxa de calor de hidratação estão exibidas na Figura 3. Nota-se que o primeiro pico ocorre em intensidades diferentes, entretanto em períodos semelhantes, exceto para as pastas com adição de $10 \%$ de lodo de ETA com e sem aditivo, onde os picos se assemelham.

As pastas com teor de $10 \%$ de lodo de ETA com e sem adição de aditivo, apresentaram pico principal em aproximadamente 10 horas, enquanto a pasta referência teve pico em aproximadamente 16 horas.

Chama a atenção a rápida liberação de calor da pasta contendo $20 \%$ de lodo de ETA sem aditivo em comparação à mesma pasta com aditivo. Enquanto a primeira teve seu pico máximo de hidratação em aproximadamente 2 horas, a segunda apresentou em 8 horas, que é relacionada ao conhecido efeito retardador de pega dos aditivos superplastificantes.

Pode-se observar que o efeito do lodo de ETA foi de acelerar e aumentar a liberação de calor. Este efeito está relacionado à alta finura das particulas de lodo, propiciando o efeito e nucleação na mistura, e também foi observado no trabalho de Ruviaro [10] .

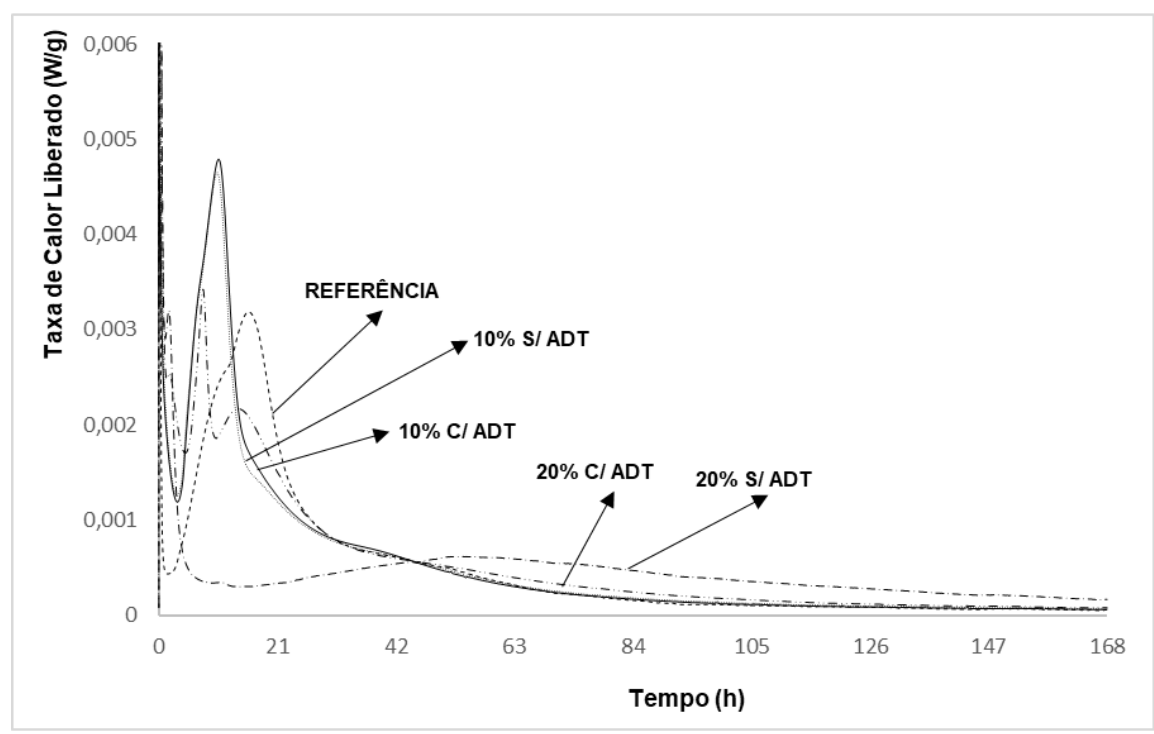

Figura 3: Curvas de hidratação das pastas. 
A Figura 4 apresenta as curvas do calor total liberado durante a hidratação das pastas após o período de 168 horas (7 dias). É possível analisar que apenas a pasta com adição de $20 \%$ de lodo de ETA (20\% S/ ADT), apresentou calor de hidratação menor do que a pasta referência.

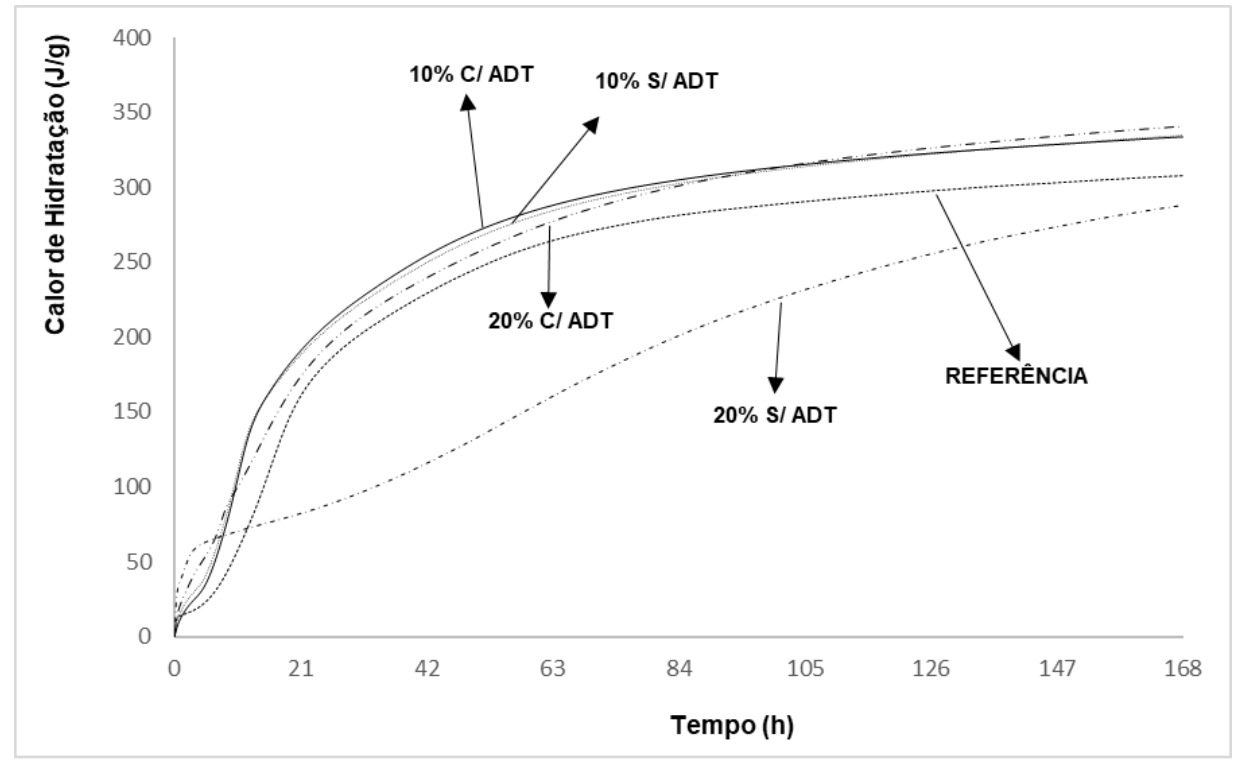

Figura 4: Curvas de taxa de calor liberado durante a hidratação.

\subsection{Estudo microestrutural das pastas}

\subsubsection{Análise por difração de Raios X (DRX)}

A técnica de difração de raios $\mathrm{X}$ foi aplicada para avaliar os compostos hidratados das pastas de cimento estudadas. A análise se deu nas amostras com 28 dias de idade, e estão apresentadas na Figura 5.

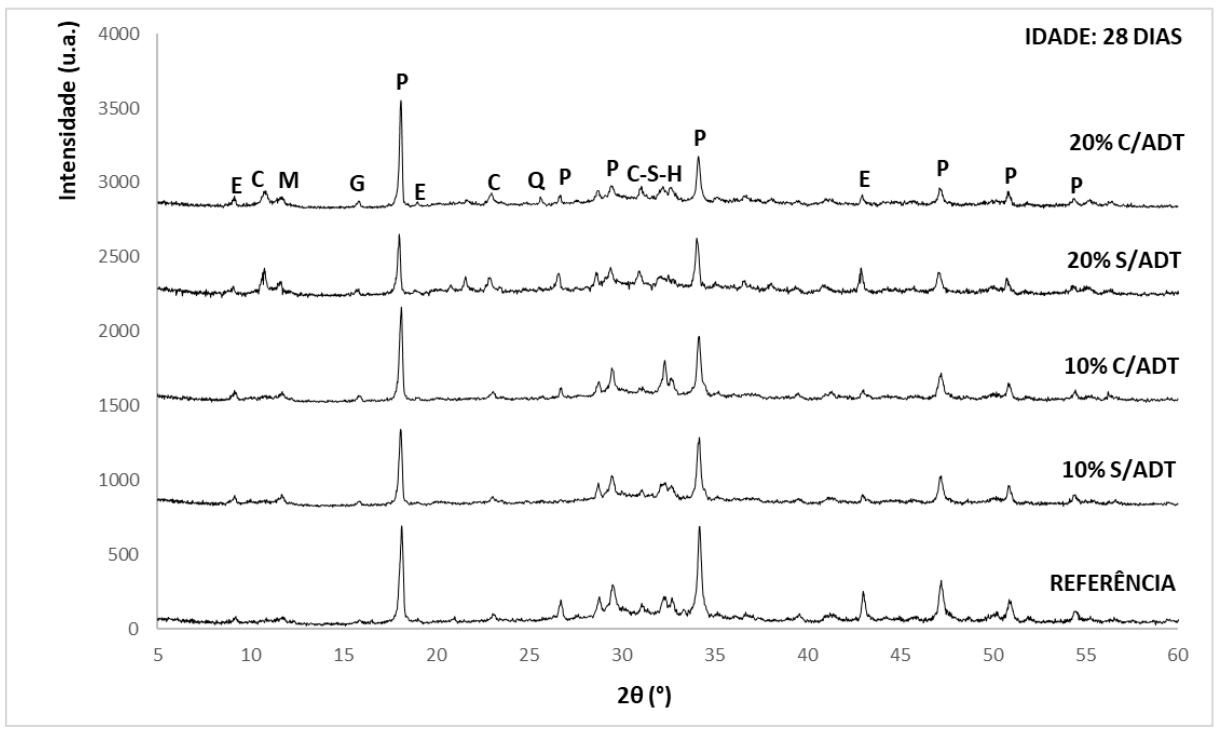

Figura 5: Difratograma das pastas, onde: $\mathrm{E}=$ Etringita; $\mathrm{P}=$ Portlandita $; \mathrm{C}=$ Caulinita; $\mathrm{C}-\mathrm{S}-\mathrm{H}=$ Silicato de cálcio hidratado; $\mathrm{Q}=$ Quartzo; $\mathrm{G}=$ Gibsita $; \mathrm{M}=$ Monossulfato de cálcio hidratado.

Observa-se no difratograma da Figura 4 a formação de portlandita e C-S-H em todas as pastas, além da presença de etringita. É possível visualizar que com o aumento do teor de lodo de ETA ao cimento, o pico correspondente ao C-S-H não sofre expressiva redução na sua intensidade. 
Um pico referente ao monossulfato de cálcio hidratado é percebido em todas as amostras. Nota-se que os picos de C-S-H e CH da pasta $20 \%$ S/ADT, se assemelham com os da pasta referência.

É importante destacar, que a intensidade dos picos de etringita, reduzem ao ser adicionado $10 \%$ de lodo de ETA na composição e aumentam nas pastas contendo $20 \%$ de lodo de ETA.

É possível visualizar um pico com pouca intensidade correspondente à gibsita apenas nas amostras contendo lodo de ETA. O principal pico do lodo de ETA o qual corresponde ao quartzo é possível notar nas amostras exceto na referência, entretanto quase imperceptível por sua baixa intensidade. Dois picos referentes à caulinita também foram identificados nas amostras contendo lodo.

Com o aumento do teor de lodo de ETA nas amostras, observa-se que os picos correspondentes à gibsita, ao quartzo e à caulinita apresentam um aumento na sua intensidade. Já para a amostra referência, ambos os picos não são observados. O ocorrido pode ser resultado da incorporação dos compostos do lodo pelo cimento nestes pontos, formando caulinita, gibsita e quartzo.

As análises de DRX mostram que o lodo foi bem incorporado pelo cimento Portland, sendo que os picos correspondentes aos principais compostos hidratados do cimento aparecem bem definidos em todas as amostras. Em relação ao processo de hidratação, ocorreu um retardo com o aumento do teor de lodo de ETA nas amostras.

\subsubsection{Análise termogravimétrica (TG) e termogravimétrica derivada (DTG)}

A Figura 6 apresenta as curvas obtidas através de análise termogravimétrica (TG) e termogravimétrica derivada (DTG), onde o pico inicial corresponde ao C-S-H, o segundo a etringita, o terceiro a portlandita e o quarto ao $\mathrm{CaCO}_{3}$.

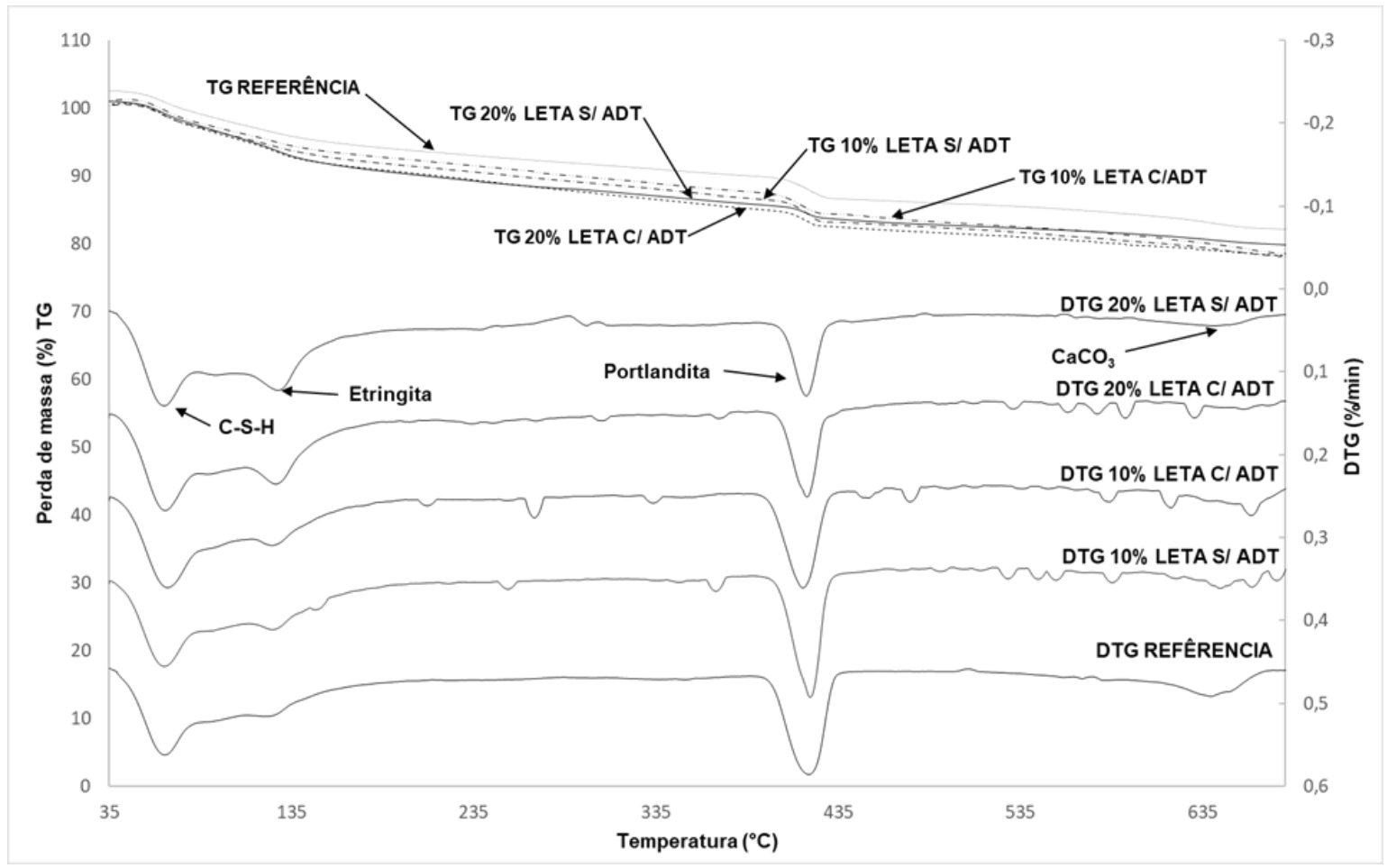

Figura 6: Curvas de TG e DTG.

$\mathrm{O}$ pico referente ao $\mathrm{C}-\mathrm{S}-\mathrm{H}$ aparece bem definido em todas as amostras. O segundo pico, referente à etringita, apresenta-se em todas as pastas, mas mostra-se bem mais definido nas amostras contendo $20 \%$ de lodo de ETA. O pico referente à portlandita também está presente em todas as amostras, entretanto diminui com o aumento do teor de lodo de ETA. O pico referente ao carbonato de cálcio $\left(\mathrm{CaCO}_{3}\right)$ aparece bem definido na pasta referência, sendo que nas outras pastas a sua presença é pouco percebida.

Através das análises de DRX e TG/DTG, é possível perceber que o lodo foi incorporado ao cimento. 


\subsubsection{Microscopia Eletrônica de Varredura (MEV)}

A microestrutura das amostras na idade de 28 dias foi avaliada através de imagens obtidas por MEV, e são expostas na Figura 7. A Figura 7a, mostra a pasta com adição de 10\% de lodo de ETA, e a Figura 7b com $20 \%$ de lodo. Percebe-se que com a adição de aditivo não ocorre fissuras nas amostras (aumento de 100 vezes), levando a concluir que o aditivo empregado se mostrou eficiente para a finalidade que foi proposto.
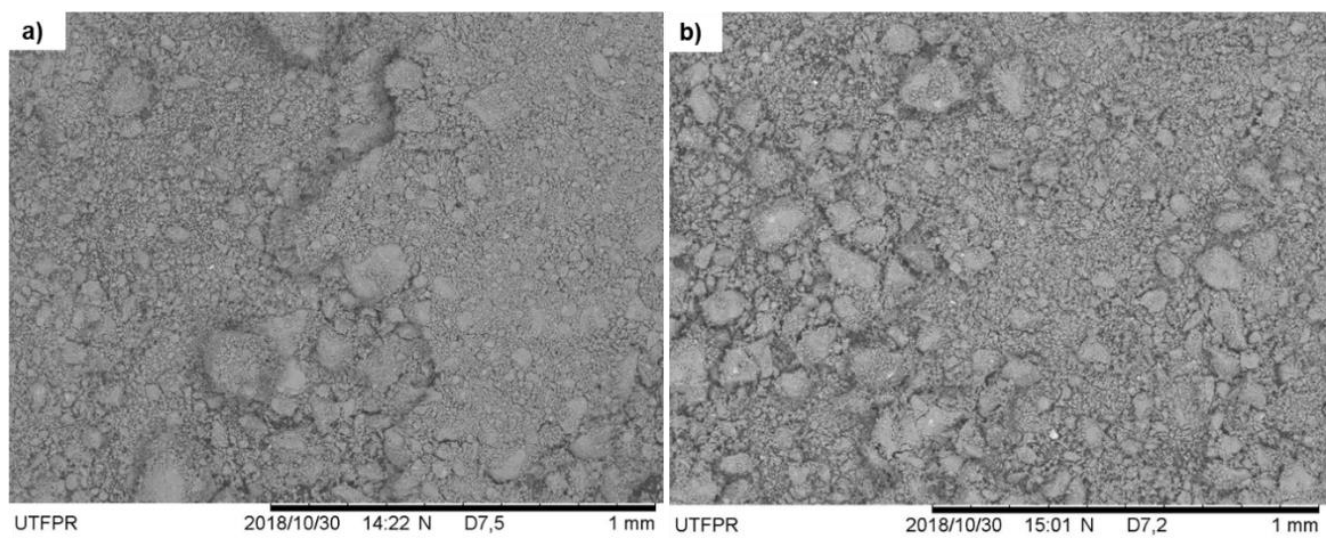

Figura 7: Micrografias das amostras com adição de lodo. a) +10\% de lodo de ETA com aditivo e b) +20\% de lodo de ETA com aditivo.

\subsection{Avaliação da resistência mecânica}

A Figura 8 apresenta a resistência mecânica para as idades de 7 e 28 dias.

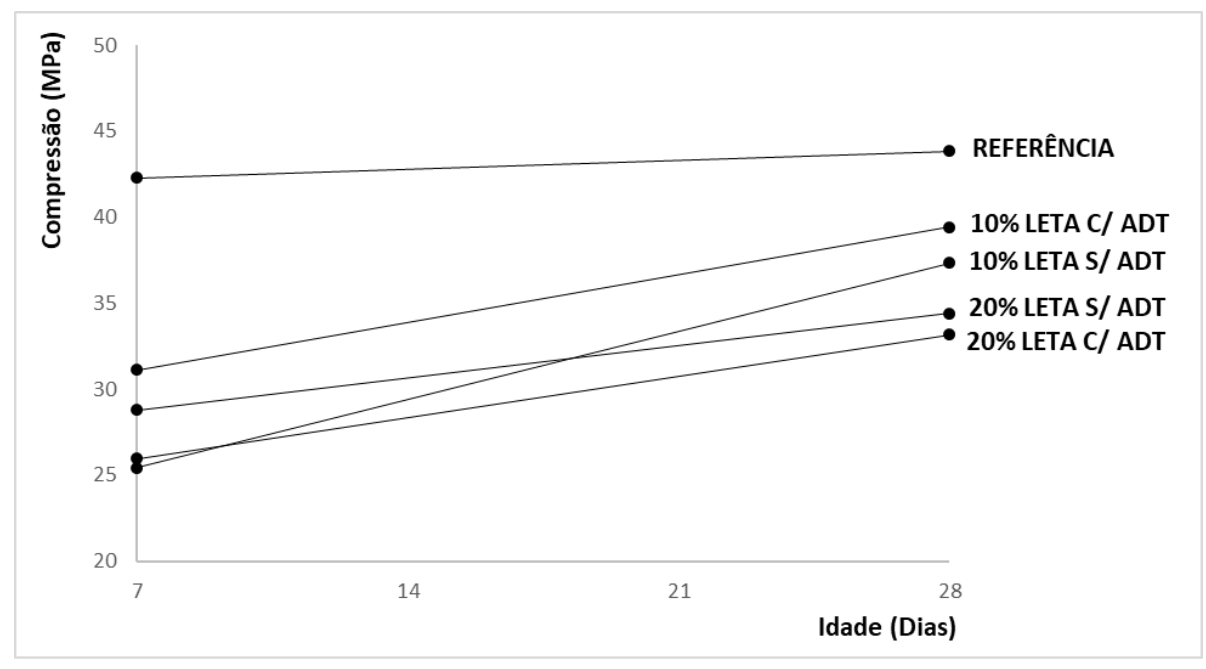

Figura 8: Resultado dos testes de resistência mecânica do CPV.

A amostra referência, apresentou resultados de 42,3 e 43,8 MPa para as idades de 7 e 28 dias respectivamente.

Na substituição do CPV por 10\% de lodo de ETA, os resultados obtidos foram de 25,4 e 37,3 MPa para as idades de 7 e 28 dias. Com adição de aditivo, o mesmo traço apresentou valores de 31,1 e 39,4 MPa para as idades de 7 e 28 dias, valores maiores do que na amostra sem aditivo.

Na substituição do CPV por $20 \%$ de lodo de ETA, os resultados obtidos foram de 28,4 e 34,4 MPa para as idades de 7 e 28 dias. Com adição de aditivo, o mesmo traço apresentou valores de 25,9 e 33,1 MPa para as idades de 7 e 28 dias, valores menores do que na amostra sem aditivo.

Pode-se observar que quanto maior o teor do lodo de ETA, maior a interferência negativa nos valores de resistência à compressão. Através de microestrutura, pode-se observar a formação da etringita nas pastas com lodo de ETA, o que pode justificar estes resultados. O lodo apresenta quase $26 \%$ de alumina, o que favorece a formação de etringita em idades tardias, cuja fenômeno é bastante conhecido na literatura e relaciona- 
do à queda de resistência. Em relação ao efeito do aditivo, para $10 \%$ de lodo de ETA, sua presença parece ter ajudado a evitar a aglomeração das partículas de resíduo, conforme também imagens no MEV. Entretanto, para o teor de $20 \%$, a presença do aditivo teve pouco efeito.

\section{CONCLUSÕES}

Em relação aos principais compostos hidratados formados durante o processo de hidratação das pastas, foram identificados através de análise de DRX: C-S-H, etringita, portlandita, e monossulfato de cálcio hidratado, compostos hidratados característicos do cimento Portland, além da caulinita, quartzo e gibsita os quais são oriundos do lodo de ETA. É possível concluir que houve boa incorporação do lodo de ETA pelo cimento Portland pois os principais compostos hidratados do cimento foram identificados na hidratação das pastas contendo lodo.

Na análise de DTG é possível perceber a maior quantidade de etringita nas amostras contento lodo de ETA, sendo que isto pode ter influenciado negativamente na capacidade de resistência mecânica das pastas. Com o aumento do teor de lodo de ETA a capacidade de resistência mecânica reduziu.

A utilização do lodo de ETA através da substituição parcial do cimento CPV-ARI é uma excelente alternativa para destino deste resíduo, já que com a adição do lodo de ETA em teor de $20 \%$ de lodo de ETA mostrou bom desempenho bons resultados mecânicos.

O presente estudo contribuiu com os estudos de disposição de lodo de ETA, já que a substituição parcial do cimento Portland por lodo de ETA sem ter sido calcinado apresentou ótimos resultados em relação ao teste de resistência mecânica, e ao analisar as análises de DRX, TG e DTG percebe-se a boa incorporação do lodo de ETA pelo cimento.

\section{BIBLIOGRAFIA}

[1] RODRIGUES, L., HOLANDA, J.N.F. "Influence of the incorporation of water treatment plant (WTP) sludge on the technological properties of soil-cement bricks", Cerâmica, São Paulo, pp.551-556, 2013.

[2] CARNEIRO, C., ANDREOLI, C.V. (Editores). Lodo de Estações de Tratamento de Água: Gestão e perspectivas Tecnológicas. Curitiba, Sanepar, Thinks Creative, 2013.

[3] ABNT. ASSOCIAÇÃO BRASILEIRA DE NORMAS TÉCNICAS. NBR 10.004: Resíduos sólidos Classificação. $2^{a}$ ed. Rio de Janeiro, 2004.

[4] INGUNZA, M.P.D., et al. "Uso de Resíduos do Saneamento na Fabricação da Cerâmica Vermelha", In: ANDREOLI, C.V. (Coord.) Alternativas de Usos de Resíduos do Saneamento. Projeto PROSAB. Rio de Janeiro, ABES, 2006. p. 283-359.

[5] ANDRADE, J.J.O., et al., "Performance of rendering mortars containing sludge from water treatment plants as fine recycled aggregate", Journal of Cleaner Production, Rio Grande do Sul, v. 192, pp.159-168, 2018.

[6] SALES, A., SOUZA, F.R, ALMEIDA, F.C.R. "Mechanical properties of concrete produced with a composite of water treatment sludge and saw dust”, Construction and Building Materials, São Carlos, SP, v. 25, p.2793-2798, 2011.

[7] RAMIREZ, K.G. "Viabilidade do Aproveitamento de Resíduo de Estação de Tratamento de Água (ETA) na Confecção de Concretos”, Dissertação de M.Sc., PPGTA. Universidade Tecnológica Federal do Paraná, Medianeira/PR, 2015.

[8] ALEXANDRE, E., et al., "Avaliação do lodo de ETA para substituição parcial do cimento Portland", In: $7^{\circ}$ International Congress on Ceramics \& $62^{\circ}$ Congresso Brasileiro de Cerâmica, 2018, Foz do Iguaçu, PR, Brasil.

[9] GODOY, L. G. G., et al., "Valorization of water treatment sludge waste by application as supplementary cementitious material", Construction and Building Materials, v. 223, pp. 939-950, 2019.

[10] RUVIARO, A. S. "Efeito da incorporação do lodo calcinado de estação de tratamento de água e fíler da casca de ovo como materiais cimentícios suplementares em matrizes de cimento Portland", Dissertação de M.Sc., PPGEC, Universidade Federal de Santa Catarina, Florianópolis/SC, 2019.

[11] ABNT. ASSOCIAÇÃO BRASILEIRA DE NORMAS TÉCNICAS. NBR 7.215: Cimento Portland Determinação da resistência à compressão. Rio de Janeiro, 1996. 


\section{ORCID}

Elisandro Alexandre

https://orcid.org/0000-0001-6834-0114

Caroline Angulski da Luz

http://orcid.org/0000-0002-8007-1620. 